\title{
Numerical variations and localization of foramen spinosum in 3D-CT images
}

\author{
Yadigar Kastamoni $^{1}$ (D), Ahmet Dursun ${ }^{1}$ (D), Veysel Atilla Ayyıldız ${ }^{2}$ (D), Kenan Öztürk ${ }^{1}$ (D) \\ ${ }^{1}$ Department of Anatomy, School of Medicine, Siileyman Demirel University, Isparta, Turkey \\ ${ }^{2}$ Department of Radiology, School of Medicine, Siileyman Demirel University, Isparta, Turkey
}

\begin{abstract}
Objectives: The structures passing through the foramen spinosum and its neurovascular relationships are of great importance for surgical approches directed to middle cranial fossa. The aim of the present study was to examine the number and location of the foramen spinosum (FS) in 3D-CT images.

Methods: The study was retrospectively conducted on 3D-CT images of 177 adults. Firstly, the transverse section passing through the upper edge of the orbit, extending parallel to the Frankfurt plane was chosen. Then, the $x$ and $y$-axes were determined on that transverse section. The coordinates, number, and location of the FS with respect to the foramen ovale (FO) were identified accordingly on $\mathrm{x}$ and $\mathrm{y}$-axes.

Results: While 1 FS was present in $90.96 \%$ of a total of 354 sides of 177 heads, there were 2 FS and 3 FS in $8.76 \%$ and $0.28 \%$ of the sides, respectively. The FS was located posterolaterally in $97.68 \%$, posteriorly in $2.06 \%$, and laterally in $0.26 \%$ with respect to the FO. In terms of FS coordinates, there was no statistically significant difference between gender and sides in the distance of the FS to the $\mathrm{x}$-axis, but there was a statistically significant difference between gender and sides in the distance of the FS to the y-axis.
\end{abstract}

Conclusion: Evaluation of the number of the FS and its location would help identifying and preserving neighbouring neurovascular structures during surgical interventions directed to the middle cranial fossa.

Keywords: computed tomography; middle cranial fossa; middle meningeal artery; skull base; sphenoid bone

Anatomy 2021;15(1):59-63 @2021 Turkish Society of Anatomy and Clinical Anatomy (TSACA)

\section{Introduction}

The skull base is divided into three cranial fossae: anterior, middle, and posterior. The region located between the small wing of the sphenoid bone and the petrous part of the temporal bone is known as the middle cranial fossa. ${ }^{[1]}$ The middle cranial fossa is clinically very significant due to the foramina it contains and the structures passing through these foramina. The complex anatomy of this region, the diversity and aggressiveness of its tumors, and the complex reconstruction process make operations on the region requiring a multidisciplinary approach difficult. Important surgical landmarks allow surgeons to have a good understanding of the anatomy, which makes it easier to plan and perform the surgical procedure. ${ }^{[2]}$

The foramen spinosum (FS) is one of the foramina located in the infratemporal surface of the great wing of the sphenoid bone and is usually located posterolateral to the foramen ovale (FO) ${ }^{[3,4]}$ The FS is one of the structures providing the connection between the infratemporal fossa and the middle cranial fossa. The middle meningeal artery, middle meningeal vein, and the meningeal branch of the mandibular nerve pass through it. $^{[5,6]}$ The FS derives from the first pharyngeal arch, also known as the mandibular arch. It starts to ossify eight months after birth, and it may take up to seven years for it to develop into a bony ring-shaped formation. ${ }^{[7,8]}$

Due to its proximity to other cranial foramina, the FS is an important landmark, especially in skull base traumas involving the middle cranial fossa and infratemporal fossa. The clinical significance of this foramen is better understood in bypass surgeries involving the petrous segment of the internal carotid artery and the posterior cerebral artery, in which the middle meningeal artery is 
used as a graft. ${ }^{[4]}$ The FS is important for various diagnostic and treatment techniques such as electroencephalographic analysis, percutaneous trigeminal rhizotomy, and percutaneous biopsy of cavernous sinus tumors. During such procedures, the middle meningeal artery can be iatrogenically injured since the FS is very close to the FO ${ }^{[4]}$ Therefore, knowledge about the location and variations of this foramen is important for neurosurgeons, radiologists, and anatomists due to the techniques available nowadays.

Different bony landmarks on 2D and 3D radiological images and dry bones used to determine the location of the foramina in previous studies. ${ }^{[9-11]}$ The developments in 3D imaging have largely improved the visualization of craniofacial structures. This imaging method allows the $3 \mathrm{D}$ coordinates of the foramina to be known. ${ }^{[12]}$

Considering the clinical significance of the FS, we aimed to examine the morphometric properties of the FS upon $3 \mathrm{D}$ reconstruction $\mathrm{CT}$ images since it helps to understand the $3 \mathrm{D}$ location of the FS in interventions to be performed in this region.

\section{Materials and Methods}

Our study was retrospectively conducted on head and neck computed tomography (CT) images. The morphometric and morphological characteristics of the FS belonging to 177 individuals (94 females, 83 males) aged between 20 and 92 years (mean age 55.06 \pm 18.83 ) were examined.

Head and neck CT images were obtained from the hospital's "Picture Archiving and Communication System" (PACS) in the Radiology Department. Patients with any tumors or fractures on head-neck CT were not included in the study. Metabolic bone conditions that might affect bone tissue in patients, such as osteoporosis, were not questioned. CT images were obtained by a multidetector 128 slice SOMATOM Definition AS Siemens (Siemens Healthcare, Erlangen, Germany) CT device using the following parameters: $120 \mathrm{kV}$, slice thickness $=1 \mathrm{~mm}$, matrix $=512 \times 512$, collimation $=128 \times 0.6$ slice increment $=0.7$ pitch $=0.8$ FOV (Field of View) (250-300). A 3D reconstruction was created from the scanned axial images using the RadiAnt DICOM Viewer (Version 2020.2; Swansea, UK) program. After the 3DCT image of the cranium was obtained, the calvaria was removed by taking a transverse section passing through the upper edge of the orbit, extending parallel to the Frankfurt plane. Then, the following axes were determined by looking at the cranium from the top.

y-axis: the sagittal axis passing through the middle of the dorsum sellae and connecting the frontmost and backmost points of the cranium (Figure 1).

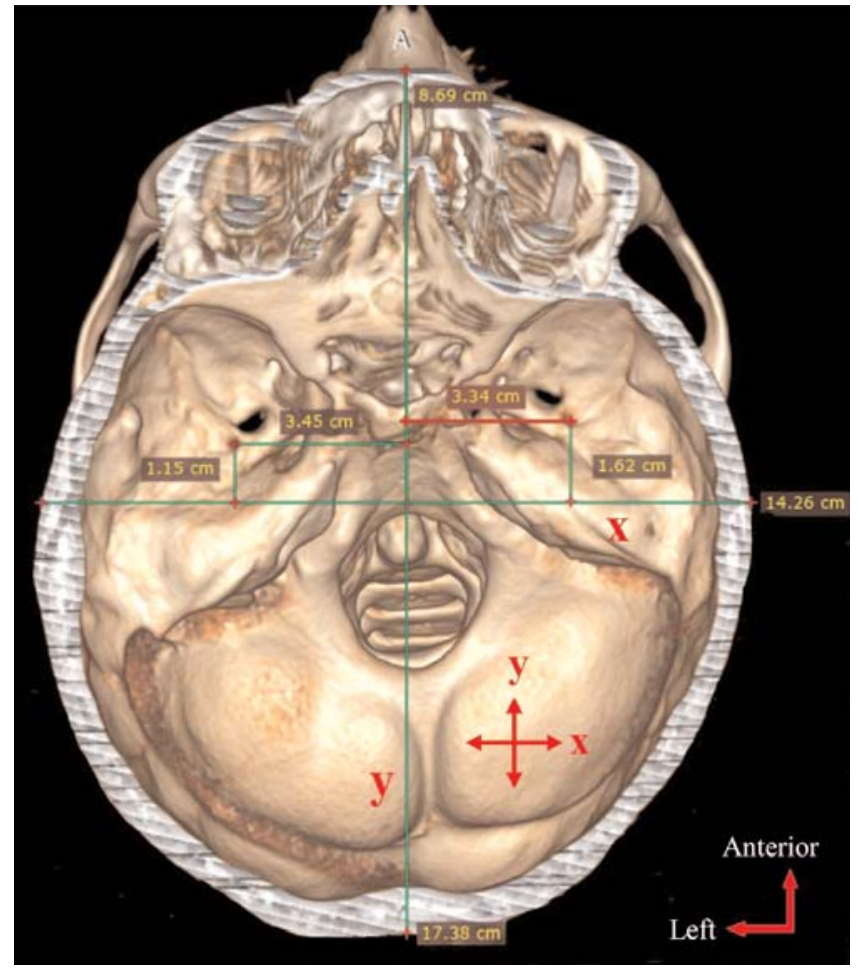

Figure 1. Distances of the foramen spinosum to the $x$ - and $y$-axes.

$\mathbf{x}$-axis: the axis extending from the middle of the $y$ axis in the transverse direction on the transverse plane (Figure 1).

The following FS morphometry-related parameters were measured:

- Coordinates of the FS (distance to $\mathrm{x}$ and $\mathrm{y}$-axes) (Figure 1)

- Number of the FS

- Location of the FS with respect to the FO

Statistical analysis was performed using SPSS for Windows 20.0 program (SPSS Inc., Armonk, NY, USA). The arithmetic means and standard deviations of all parameters were calculated according to the sides and sex. In pairwise comparisons, the independent samples t-test was used for the normally distributed parameters, and the Mann-Whitney $U$ test was used for the non-normally distributed parameters.

\section{Results}

While 1 FS was present in $90.96 \%(n=322)$ of 354 sides of 177 heads, 2 FS and 3 FS were present in $8.76 \%$ $(n=31)$ and $0.28 \%(n=1)$ of them, respectively. When the location of the FS with respect to the FO was examined, it was observed that the FS was located posterolaterally 
Table 1

Averages and $p$ values of foramen spinosum according to sex and sides.

\begin{tabular}{|c|c|c|c|c|c|c|c|c|}
\hline Parameters & Sex & $\mathbf{n}$ & Mean \pm SD & $\mathbf{p}$ & Side & $\mathbf{n}$ & Mean \pm SD & p \\
\hline \multirow[t]{2}{*}{ Distance of the FS to the $x$-axis $(\mathrm{cm})$} & $\mathrm{F}$ & 94 & $0.95 \pm 0.39$ & \multirow{2}{*}{0.670} & $\mathrm{R}$ & 177 & $0.92 \pm 0.40$ & \multirow{2}{*}{0.310} \\
\hline & M & 83 & $0.93 \pm 0.41$ & & L & 177 & $0.96 \pm 0.40$ & \\
\hline \multirow[t]{2}{*}{ Distance of the FS to the $y$-axis $(\mathrm{cm})$} & $\mathrm{F}$ & 94 & $3.08 \pm 0.20$ & \multirow{2}{*}{$<0.001^{*}$} & $\mathrm{R}$ & 177 & $3.19 \pm 0.25$ & \multirow{2}{*}{$0.020^{*}$} \\
\hline & M & 83 & $3.24 \pm 0.26$ & & $\mathrm{~L}$ & 177 & $3.12 \pm 0.22$ & \\
\hline
\end{tabular}

${ }^{*} \mathrm{p}<0.05$. F: female; FS: foramen spinosum; L: left; M: male; R: right; SD: standard deviation.

in $97.68 \%(n=379)$, posteriorly in $2.06 \%(n=8)$, and laterally in $0.26 \%(\mathrm{n}=1)$ with respect to the FO.

The distance of the FS to the $\mathrm{x}$ and $\mathrm{y}$-axes was compared by giving averages according to sex and sides (Table 1). Accordingly, there was no statistically significant difference between gender $(\mathrm{p}=0.670)$ and sides $(p=0.310)$ in the distance of the FS to the $x$-axis parameter. In the distance of the FS to the $y$-axis parameter, a statistically significant difference was found between gender $(\mathrm{p}<0.001)$ and sides $(\mathrm{p}=0.020)$ (Figure 2).

\section{Discussion}

Due to the advantages of 3D imaging, it is recommended for clinicians to learn to use $3 \mathrm{D}$ reconstruction imaging sources effectively and move away from conventional 2D imaging methods. ${ }^{[12]}$ In light of this information, the FS coordinates in our study were obtained using the $3 \mathrm{D}$ imaging method and different landmark points (coordinate system) from previous studies. There are many studies based on measuring the distance between the FS and other anatomical structures. ${ }^{[6,9,13]}$ However, the variations of other anatomical structures with the measured distances were ignored in these studies. Therefore, the coordinate system, which was considered least affected by the variations, was used in our study.

Some authors indicated that the differences in the skull base foramina could be considered a variation for some populations due to the evolutionary process. ${ }^{[14,15]}$ Tewari et al. $^{[4]}$ indicated that the FS-related anatomical variations were associated with ethnic differences, incomplete osteogenesis, or abnormal development of the middle meningeal artery. Some authors reported that the diversity in the knowledge of the FS might be the result of factors such as age, sex, or population and differences in reference points taken as criteria in measurements. ${ }^{[10]}$

Many studies have been conducted on the number of the foramen spinosum. [3, $, 7,10,14,16-20]$ The comparison of the results of those studies with the results of our study is presented in Table 2. Duplication of FS varies between
$0-8.76 \%$. We suggest that this variation may be due to the difference in the population on which the study was conducted, the difference in the method used in the study, the number of materials used, and the subjective interpretation of the researchers who conducted the study. The absence rate of FS is $0-2.85 \%$. We had no cases in which FS was absent, as in the studies carried out by Tewari et al. $^{[4]}$ and Osunwoke et al. ${ }^{[10]}$ On the other hand, we observed 3 FS in one sample, similar to the findings obtained by Lazarus et al. ${ }^{[14]}$

The variations in the presence, absence, and the number of the FS are very important for the supply of the dura mater since they may accompany variations such as; the early branching of the middle meningeal artery, a meningeal artery passing through the foramen ovale, a meningeal artery emerging from the ophthalmic artery, or passing through the superior orbital fissure as a branch of the maxillary artery. ${ }^{[7,9,20]}$

The FS is usually known as it is located posterolateral to the FO ${ }^{[4]}$ However, as can be seen in our study, the FS location with respect to the FO varies. According to our results, the FS was located posterolateral to the FO by $97.68 \%$, posterior to it by $2.06 \%$, and lateral to it by

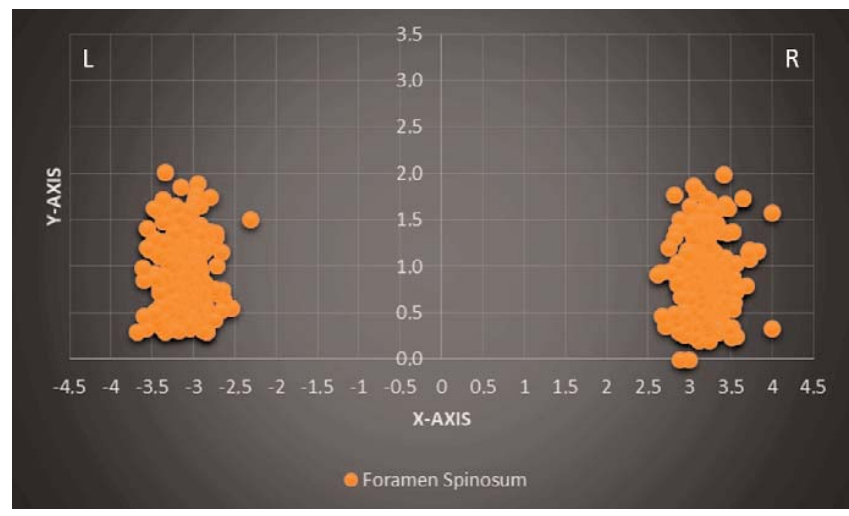

Figure 2. The distribution chart of the localizations of the foramen spinosum according to the $x$ and $y$-axes ( $R$ : right, $L$ : left). 
Table 2

Comparison of studies on the number of foramen spinosum.

\begin{tabular}{|c|c|c|c|c|c|}
\hline \multirow[b]{2}{*}{ Authors } & \multirow[b]{2}{*}{ Number of sides } & \multicolumn{4}{|c|}{ Number of foramen spinosum (\%) } \\
\hline & & Absent & 1 & 2 & 3 \\
\hline Our study & 354 & - & 90.96 & 8.76 & 0.28 \\
\hline Khaimar and Bhusari ${ }^{[3]}$ & 186 & 0.54 & 96.23 & 3.23 & - \\
\hline Tewari et al ${ }^{[4]}$ & 126 & - & 100 & - & - \\
\hline Sophia and Kalpana ${ }^{[7]}$ & 80 & 2.5 & 93.75 & 3.75 & - \\
\hline Osunwoke et al. ${ }^{[10]}$ & 174 & - & 100 & - & - \\
\hline Lazarus et al. ${ }^{[14]}$ & 200 & 2 & 95 & 2.5 & 0.5 \\
\hline Javed et al. ${ }^{[16]}$ & 70 & 1.43 & 90 & 8.57 & - \\
\hline Farooq et al. ${ }^{[17]}$ & 40 & 2.5 & 95 & 2.5 & - \\
\hline Kulkarni and Nikade ${ }^{[18]}$ & 200 & 2.5 & 97.5 & - & - \\
\hline Rai et al. ${ }^{[19]}$ & 70 & 2.85 & - & 2.85 & - \\
\hline Khan et al. ${ }^{[20]}$ & 50 & 2 & 96 & 2 & - \\
\hline
\end{tabular}

$0.26 \%$. Lazarus et al. ${ }^{[14]}$ reported that the FS was located posterolateral to the FO by $97.53 \%$, posterior to it by $1.97 \%$, and posteromedial to it by $0.5 \%$. The results of both studies are considerably similar. Differently, while no FS located posteromedial to the FO in our cases, no FS located lateral to the $\mathrm{FO}$ as revealed Lazarus et al. ${ }^{[14]}$ Although the location of the FS lateral or posteromedial to the FO is rare, these possible locations should also be taken into account. Particularly, considering the structures passing through the FS and neurovascular structures to which it is adjacent, it is very important to have full knowledge of the FS location in any intervention to be performed to this region.

Boduç and Öztürk ${ }^{[21]}$ revealed that the FS was symmetrical in 14 of 133 skulls and asymmetrical in the remaining part. Likewise, in our study, a difference was found between the right and left sides in the FS distance to the $y$-axis. In our samples, the FS was further away from the $y$-axis on the right side than on the left side. Unlike our study, Somesh et al. ${ }^{[2]}$ reported that the FS on the left side was far from the midline. We think that the difference in the results of both studies may be due to the difference in the studied population, the different number of samples studied, the difference of the method used, and the lack of knowledge about factors such as age and sex in the study performed by Somesh et al. ${ }^{[2]}$ Since the difference between the right and left sides of the FS affects the location of the middle meningeal artery, it should be considered, especially in surgical interventions to be performed in this region.

\section{Conclusion}

We suggest that our study may contribute to future studies on the FS and the middle meningeal artery passing through it. The knowledge of the normal and variational anatomy of the FS may prevent misinterpretation during imaging procedures such as $\mathrm{CT}$ and magnetic resonance imaging. Furthermore, the evaluation of the FS number, its relationship with the FO, and its location will be an important guide for surgeons to identify and protect neurovascular structures, especially during surgical interventions to the middle cranial fossa.

\section{Conflict of Interest}

The authors declare that they have no conflict of interest.

\section{Author Contributions}

YK: project development, data collection, data analysis, interpretation of the results, manuscript writing; $\mathrm{AD}$ : project development, data collection, manuscript editing; VAA: data collection, manuscript reviewing; KÖ: data analysis, manuscript reviewing.

\section{Ethics Approval}

Approval for this study was obtained from the Clinical Research Ethics Committee of Süleyman Demirel University, Faculty of Medicine (Date: 16 April 2020, Decision No: 109).

\section{Funding}

This research received no specific grant from any funding agency in the public, commercial, or not-for-profit sectors. 


\section{References}

1. Karthikeyan G, Sankaran PK, Raghunath G, Yuvaraj M, Arathala R. Morphometric study of various foramina in the middle cranial fossa of the human skull. Indian Journal of Clinical Anatomy and Physiology 2017;4:574-8.

2. Liu Z, Yi Z. A new bony anatomical landmark for lateral skull base surgery. J Craniofac Surg 2020;31:1157-60.

3. Khairnar KB, Bhusari PA. An anatomical study on the foramen ovale and the foramen spinosum. J Clin Diagn Res 2013;7:427-9.

4. Tewari S, Gupta C, Palimar V, Kathur SG. Morphometric analysis of foramen spinosum in South Indian population. Acta Medica Iranica 2018;56:113-8.

5. Krishnamurthy J, Chandra L, Rajanna S. Morphometric study of foramen spinosum in human skulls. International Journal of Current Research and Review 2013;5:44-8.

6. Saheb SH, Khaleel N, Havaldar PP, Shruthi BN. Morphological and morphometric study of foramen spinosum. International Journal of Anatomy and Research 2017;5:4523-6.

7. Sophia MM, Kalpana R. A study on foramen spinosum. International Journal of Health Sciences and Research 2015;5:187-93.

8. White HJ, Reddy V, Mesfin FB. Anatomy, head and neck, foramen spinosum. In: StatPearls [Internet]. Treasure Island (FL): StatPearls Publishing; 2021 [Internet]. Available from: https://www.ncbi.nlm. nih.gov/books/NBK535432/

9. Krayenbühl N, Isolan GR, Al-Mefty O. The foramen spinosum: a landmark in middle fossa surgery. Neurosurg Rev 2008;31:397-402.

10. Osunwoke EA, Mbadugha CC, Orish CN, Oghenemavwe EL, Ukash CJ. A morphometric study of foramen ovale and foramen spinosum of the human sphenoid bone of southern Nigerian population. Journal of Applied Biosciences 2010;26:1631-5.

11. Zhu HY, Zhao JM, Yang M, Xia CL, Li YQ, Sun H, Zhang YQ, Tian Y. Relative location of foramen ovale, foramen lacerum, and foramen spinosum in hartel pathway. J Craniofac Surg 2014;25: $1038-40$.

12. Lagravere MO, Gordon JM, Flores-Mir C, Carey J, Heo G, Majorf $\mathrm{PW}$. Cranial base foramen location accuracy and reliability in cone- beam computerized tomography. Am J Orthod Dentofacial Orthop 2011;139:e203-10.

13. Baur DA, Beushausen M, Leech B, Quereshy F, Fitzgerald N. Anatomic study of the distance between the articular eminence and foramen spinosum and foramen spinosum and petrotympanic fissure. J Oral Maxillofac Surg 2014;72:1125-9.

14. Lazarus L, Naidoo N, Satyapal KS. An osteometric evaluation of the foramen spinosum and venosum. International Journal of Morphology 2015;33:452-8.

15. Sharma NA, Garud RS. Morphometric evaluation and a report on the aberrations of the foramina in the intermediate region of the human cranial base: a study of an Indian population. European Journal of Anatomy 2011;15:140-9.

16. Javed M, Rehman Z, Iftikhar S, Naz F, Junaid SM, Alam A. Anatomical variations of foramen ovale and foramen spinosum in dry human skull. Journal of Khyber College of Dentistry 2020;2:Article No20. p.1-3 [Available from: http://www.jkcd.kcd.edu.pk/issues/ PublishedOnline2020Vol01/JKCD-OnlinePub2020-V2-No24.pdf]

17. Farooq B, Gupta S, Raina S. Anatomic variations in foramen ovale and foramen spinosum. JK Science 2018;20:112-5.

18. Kulkarni SP, Nikade VV. A morphometric study of foramen ovale and foramen spinosum in dried indian human skulls. International Journal of Recent Trends in Science and Technology 2013;7:74-5.

19. Rai AL, Gupta N, Rohatgi R. Anatomical variations of foramen spinosum. Innovative Journal of Medical and Health Science 2012;2:86-8.

20. Khan AA, Asari MA, Hassan A. Anatomical variants of foramen ovale and spinosum in human skulls. International Journal of Morphology 2012;30:445-9.

21. Boduç E, Öztürk L. Morphometric evaluation of foramen spinosum [Article in Turkish]. Kafkas Journal of Medical Sciences 2020;10:604.

22. Somesh MS, Murlimanju BV, Krishnamurthy A, Sridevi HB. An anatomical study of foramen spinosum in South Indian dry skulls with its emphasis on morphology and morphometry. International Journal of Anatomy and Research 2015;3:1034-8.
ORCID ID:

Y. Kastamoni 0000-0002-3504-5853; A. Dursun 0000-0003-4568-8761; V. A. Ayyldız 0000-0003-0252-9023; K. Öztürk 0000-0002-5552-8684
Correspondence to: Yadigar Kastamoni, PhD Department of Anatomy, Faculty of Medicine, Süleyman Demirel University, Isparta, 32260, Turkey

Phone: +902462113302

e-mail: yadigarkastamoni@hotmail.com

Conflict of interest statement: No conflicts declared.

This is an open access article distributed under the terms of the Creative Commons Attribution-NonCommercial-NoDerivs 4.0 Unported (CC BY-NCND4.0) Licence (http://creativecommons.org/licenses/by-nc-nd/4.0/) which permits unrestricted noncommercial use, distribution, and reproduction in any medium, provided the original work is properly cited. How to cite this article: Kastamoni Y, Dursun A, Ayylldız VA, Öztürk K. Numerical variations and localization of foramen spinosum in 3D-CT images. Anatomy 2021;15(1):59-63. 